\title{
Oxidative Modification of Low-Density Lipoprotein in Relation to Dyslipidemia and Oxidant Status in Children With Steroid Sensitive Nephrotic Syndrome
}

\author{
NAGLA T. EL-MELEGY, NAGWA A. MOHAMED, AND MOHMED M. SAYED \\ Departments of Biochemistry [N.T.E.-M.] and Pediatrics [N.A.M., M.M.S.], Assiut University, Assiut 71515, Egypt
}

\begin{abstract}
It has been proposed that nephrotic syndrome is a consequence of an imbalance between oxidant/antioxidant statuses. The present study aimed to assess oxidant and antioxidant status in relation to dyslipidemia in children during remission and relapse phases of steroid sensitive nephrotic syndrome (SSNS). The study dealt with 40 children diagnosed as SSNS. They were categorized into two subgroups. The first subgroup included 25 children during remission stage. The second subgroup included 15 children during relapse. Control group consisted of age and gender-matched 15 healthy children. Significantly higher serum levels of malondialdehyde, oxidized LDL, total cholesterol, LDL cholesterol, triglycerides, apolipoprotein A-I, and apolipoprotein-B were observed in patients with SSNS especially in the relapsers. The serum levels of albumin, glutathione peroxidase activity, vitamin $\mathrm{C}, \mathrm{A}$, and E, and HDL cholesterol were significantly lower in patients especially among relapsers. In conclusion, a strong relationship between the oxidant/ antioxidant status and dyslipidemia is documented in patients with SSNS, especially among relapsers. No normalization of the biochemical indices was observed despite the use of glucocorticoids. Therefore, the combined use of steroid, antioxidant therapy, and lipid lowering therapy can be recommended in such children. (Pediatr Res 63: 404-409, 2008)
\end{abstract}

$\mathrm{M}^{\prime}$ inimal change nephrotic syndrome (MCNS) is the most common form of nephrotic syndrome (NS) in children and generally responds well to treatment with prednisone (1). An important advance in understanding the pathogenesis of NS was the observation that oxygen-free radicals are possible mediators of injury in experimental nephrosis in rats. The similarity of that animal model to human MCNS provokes the idea that free-radical mediated injury could play a role in the pathogenesis of that disorder (2). This is probably a consequence of an imbalance between oxidant and antioxidant activity in vivo (3). The injection of antioxidants in experimental models of NS has been found to be ameliorative (4). It has been suggested that enhanced permeability of the glomerular capillary wall is possibly influenced by the generation of free radicals (5). Furthermore, dyslipidemia of NS is, also, known to be linked to oxidative reactions and atherosclerosis $(6,7)$. Patients with NS have elevated concentrations of total cholesterol (TC), LDL cholesterol

Received January 31, 2007; accepted November 7, 2007.

Correspondence: Nagla T. El-Melegy, Ph.D., Biochemistry Department, Faculty of Medicine, Assiut University, Assiut, Egypt; e-mail: elmelegynagla@yahoo.com

DOI: 10.1203/PDR.0b013e3181647af5
(LDL-C), and triglycerides (TG), whereas, HDL cholesterol (HDL-C) has variously been reported to be increased, decreased, or normal (7). These abnormalities suggest that nephrotic patients have a higher risk in developing atherosclerosis (8). Both the lipid and the protein moieties of LDL-C are subject to oxidation and both can be oxidized in vivo. Oxidation of LDL-lipid moiety (oxLDL) is commonly thought to represent the initial step of oxidative LDL modification. The oxidative modification of LDL may represent an important pathway in the pathogenesis of atherogenesis (9). Direct assessment of reactive oxygen species (ROS) is not feasible because of the extremely short half-life of the free radicals (6). Therefore, the oxidative activity must be measured indirectly by the levels of lipid membranes peroxidation by-product; malondialdehyde (MDA). Also, by measuring the levels of antioxidant substances $e . g$., glutathione peroxidase (GSH-PX) (E.C.I.11.1.9) which is one of the most important scavenging enzymes (10), antioxidant vitamins (vitamins C, A, and $\mathrm{E}$ ) and albumin which is a nonenzymatic antioxidant protein.

The present study aimed to assess oxidant (in terms of serum levels of MDA and oxLDL) and antioxidant status (in terms of serum levels of albumin, GSH-PX, and vitamins C, A, and E) in relation to dyslipidemia [in terms of serum levels of TC, LDL-C, HDL-C, TG, apolipoprotein A-I (apo-A-I), and apolipoprotein-B (apo-B)] in children during remission and relapse phases of steroid sensitive nephrotic syndrome (SSNS).

\section{METHODS}

The present study was conducted on 40 children ( 22 boys/18 girls) diagnosed as SSNS. They were admitted to Pediatric University Hospital, Assiut University. Their ages ranged 5-9 y. They were categorized into two subgroups. The first subgroup included 25 children during remission stage (after $6 \mathrm{wk}$ of regular dose $2 \mathrm{mg} / \mathrm{kg} / \mathrm{d}$ of prednisolone therapy alone). Their age (mean $\pm \mathrm{SD}$ ) was $7.16 \pm 0.95 \mathrm{y}$. The second subgroup included 15 children during relapse ( 8 infrequent relapsers: patients who developed relapse once/y and 7 frequent relapsers: patients who developed relapse three times or more/y). Their age (mean \pm SD) was $6.66 \pm 1.11 \mathrm{y}$. Kidney biopsy was not performed for the studied patients.

\footnotetext{
Abbreviations: apo-A-I, apolipoprotein A-I; apo-B, apolipoprotein-B; CETP, cholesterol ester transfer protein; GSH-PX, glutathione peroxidase; HDL-C, high-density lipoprotein cholesterol; HMG-CoA, hydroxy methyl glutaryl-CoA; LpL, lipoprotein lipase; LDL-C, low-density lipoprotein cholesterol; MDA, malondialdehyde; MCNS, minimal change nephrotic syndrome; oxLDL, oxidized low-density lipoprotein; ROS, reactive oxygen species; SSNS, steroid sensitive nephrotic syndrome; TC, total cholesterol; TG, triglycerides; VLDL-C, very Low-density lipoprotein cholesterol
} 
Exclusion criteria were children with (i) Steroid resistant NS and NS secondary to renal involvement of systemic diseases; (ii) acute infection; (iii) features suggestive of chronic renal failure; and (iv) clinical and anthropometric features of malnutrition and/or signs of vitamin deficiency. In addition, a control group of 15 healthy age (mean $\pm \mathrm{SD}, 7.43 \pm 1.19 \mathrm{y}$ ) and gender ( 9 boys $/ 6$ girls) matched children were included. All the studied groups belong to a homogenous population with no difference in their cultural or socioeconomic status (to ensure minimal nutritional differences between the studied groups).

An informed written consent was obtained from the parents of each subject and the Ethics Committee of the Faculty of Medicine at Assiut University approved the study.

After an overnight fast, $5 \mathrm{~mL}$ venous blood was collected from each subject. The blood was allowed to clot at room temperature and centrifuged at $5000 \mathrm{rpm}$ for $10 \mathrm{~min}$, and then the serum was collected and kept frozen at $-70^{\circ} \mathrm{C}$ in aliquots until the time of assay of the following biochemical parameters.

Serum MDA was estimated according to the method described by Buege and Aust (11). Oxidized LDL was estimated by using the Immulisa antioxLDL antibody ELISA kit (Cat. No.1158; IMMCO Diagnostic, Inc., NY) (12). Serum albumin was determined colormetrically by a commercial kit supplied by Spectrum (ALB 080) Egypt (13). Serum GSH-PX activity was determined according to the method of Mills (14) and as modified by Hafeman et al., (15). Vitamin C was determined by the 2, 4 dinitrophenylhydrazin method of Roe (16). The method used for vitamin A determination was described by Nino and Parasad (17). Vitamin E (tocopherols) was determined according to the method of Baker et al., (18). Serum levels of LDL-C were determined as the difference between TC and the cholesterol contents of the supernatant fluid after precipitation of the LDL fraction by polyvinyl sulfate (Quimica Clinica Aplicada, Spain) (19). Serum HDL-C was determined colormetrically by using Stanbio HDL-C kit (Cat. No. 6599; Quimica Clinica Aplicada, Spain) (20). TC and TG serum levels were measured by colorimetric method using kit supplied by Stanbio Laboratory Inc. [Cat. No. 1010-430 (21) and 2100-430 (22), respectively]. Serum apo-A-I and apolipoprotein $\mathrm{B}$ were determined by radial immunodiffusion plates (Diffu-plate) provided by Biosentifica, Buenos Aires, Argentina (23).

Statistical analysis. The statistical analysis was done using Statistical Package for Social Science (SPSS) version 12. Data were expressed as mean $\pm \mathrm{SD}$. Normally distributed data were analyzed using student $t$-test whereas abnormally distributed data (skewed) were statistically analyzed using Mann Whitney test. Spearman correlation coefficient between measured parameters was evaluated by the statistical significance of their linear regression. $p$ value of less than 0.05 is considered significant.

\section{RESULTS}

The serum levels (mean \pm SD and range) of MDA and oxLDL in controls and children with SSNS at remission and relapse are presented in Table 1. Significant higher levels of MDA and oxLDL were observed in children with SSNS at both remission and relapse in comparison with those of the controls $(p<0.001)$, with significant higher levels $(p<$ 0.001 ) in relapse group in comparison with those of the

Table 1. Serum levels of malondialdehyde (MDA) and oxidized $L D L$ in controls and children with steroid sensitive nephrotic syndrome at remission and relapse

\begin{tabular}{lccc}
\hline \multicolumn{1}{c}{ Variables } & $\begin{array}{c}\text { Controls } \\
(n=15)\end{array}$ & $\begin{array}{c}\text { Remission } \\
(n=25)\end{array}$ & $\begin{array}{c}\text { Relapse } \\
(n=15)\end{array}$ \\
\hline MDA nmol/mL & & & \\
$\quad$ Mean $\pm \mathrm{SD}$ & $2.27 \pm 0.99$ & $4.94 \pm 2.12$ & $9.37 \pm 2.68$ \\
Range & $0.8-4.0$ & $2.0-10.0$ & $\begin{array}{c}4.5-13.0 \\
* p<0.001\end{array}$ \\
& & $\begin{array}{c}* p<0.001 \\
\dagger p<0.001\end{array}$ \\
Oxidized LDL EU/mL & & & \\
$\quad$ Mean $\pm \mathrm{SD}$ & $20.26 \pm 6.08$ & $45.04 \pm 7.88$ & $66.40 \pm 9.25$ \\
Range & $10.0-30.0$ & $35.0-60.0$ & $50.0-80.0$ \\
& & $* p<0.001$ & $* p<0.001$ \\
& & & $\dagger p<0.001$ \\
\hline
\end{tabular}

\footnotetext{
* Compared with controls.
}

$\dagger$ Remission versus relapse.
Table 2. Serum levels of albumin, glutathione peroxidase activity and vitamins $C, A$, and $E$ in controls and in children with steroid sensitive nephrotic syndrome at remission and relapse

\begin{tabular}{|c|c|c|c|}
\hline Variables & $\begin{array}{l}\text { Controls } \\
(n=15)\end{array}$ & $\begin{array}{l}\text { Remission } \\
(n=25)\end{array}$ & $\begin{array}{l}\text { Relapse } \\
(n=15)\end{array}$ \\
\hline \multicolumn{4}{|l|}{ Albumin $\mathrm{g} / \mathrm{dL}$} \\
\hline Mean \pm SD & $3.51 \pm 0.473$ & $3.25 \pm 0.457$ & $1.75 \pm 0.472$ \\
\hline \multirow[t]{2}{*}{ Range } & $3.0-4.5$ & $2.7-4.0$ & $1.0-2.5$ \\
\hline & & $* p$ NS & $\begin{array}{l}* p<0.001 \\
\dagger p<0.001\end{array}$ \\
\hline \multicolumn{4}{|c|}{$\begin{array}{l}\text { Glutathione peroxidase } \\
\mathrm{mU} / \mathrm{mL}\end{array}$} \\
\hline Mean \pm SD & $219.66 \pm 20.74$ & $173.04 \pm 19.43$ & $121.53 \pm 18.07$ \\
\hline \multirow[t]{2}{*}{ Range } & $180-250$ & $140-200$ & $100-150$ \\
\hline & & ${ }^{*} p<0.001$ & $\begin{array}{l}* p<0.001 \\
\dagger p<0.001\end{array}$ \\
\hline \multicolumn{4}{|c|}{ Vitamin-C mg/dL } \\
\hline Mean $\pm S D$ & $0.516 \pm 0.069$ & $0.385 \pm 0.045$ & $0.258 \pm 0.030$ \\
\hline \multirow[t]{2}{*}{ Range } & $0.40-0.65$ & $0.30-0.45$ & $0.20-0.30$ \\
\hline & & $* p<0.001$ & $\begin{array}{l}* p<0.001 \\
\dagger p<0.001\end{array}$ \\
\hline \multicolumn{4}{|c|}{ Vitamin-A mg/dL } \\
\hline Mean \pm SD & $57.53 \pm 12.43$ & $36.12 \pm 6.11$ & $27.00 \pm 5.59$ \\
\hline \multirow[t]{2}{*}{ Range } & $35.0-75.0$ & $25.0-45.0$ & $15.0-35.0$ \\
\hline & & $* p<0.001$ & $\begin{array}{l}* p<0.001 \\
\dagger p<0.001\end{array}$ \\
\hline \multicolumn{4}{|l|}{ Vitamin-E mg/dL } \\
\hline Mean \pm SD & $0.933 \pm 0.351$ & $0.78 \pm 0.17$ & $0.58 \pm 0.12$ \\
\hline \multirow[t]{2}{*}{ Range } & $0.50-1.6$ & $0.50-1.2$ & $0.40-0.80$ \\
\hline & & $* p$ NS & $\begin{array}{l}* p<0.001 \\
\dagger p<0.001\end{array}$ \\
\hline
\end{tabular}

\footnotetext{
* Compared with controls.

$\dagger$ Remission versus relapse.

NS indicates not significant.
}

remission group. Table 2 demonstrates the serum levels (mean \pm SD and range) of albumin, GSH-PX activity, and vitamins $\mathrm{C}, \mathrm{A}$, and $\mathrm{E}$ in controls and in children with SSNS at remission and relapse. Children at remission showed significant lower levels of GSH-PX activity $(p<0.001)$, vitamin-C $(p<0.001)$, vitamin-A $(p<0.001)$, and vitamin-E $(p<0.05)$ in comparison with those of the controls, except for albumin, which showed no significant difference. The relapse group showed significantly lower levels of the studied bioindices in comparison with those of the controls $(p<0.001)$ and remission $(p<0.001)$. The serum levels of TC, LDL-cholesterol (LDL-C), HDL-cholesterol (HDL-C), triglycerids (TG), apoA-I (apo A-I), and apolipoprotein B (apo-B) in controls and children with SSNS at remission and relapse are presented in Table 3. Both the studied groups of SSNS children showed significant higher levels of the studied parameters in comparison with those of the controls, except HDL-C, whose mean levels in both the SSNS groups were significantly lower than the controls. Children at relapse showed significantly higher mean levels of TC, LDL-C, and TG and significantly lower mean levels of HDL-C in comparison with those of the remission group ( $p<0.001$ ), except for apo-A-I and apo-B levels that showed no significant difference. Correlations among various studied bioindices in children with SSNS are presented in Table 4. Significant positive correlations were observed between serum levels of MDA, oxLDL, TC, LDL-C, apo-A-I, and apo-B. In addition, each of the MDA and oxLDL 
Table 3. Serum levels of total cholesterol (TC), low-density lipoprotein-cholesterol ( $L D L-C)$, high-density lipoprotein-cholesterol (HDL-C), triglycerides (TG), apolipoprotein A-I (apo A-I) and apolipoprotein $B$ (apo-B) in $A$ and $E$ in controls and children with steroid sensitive nephrotic syndrome at remission and relapse

\begin{tabular}{|c|c|c|c|}
\hline Variables & $\begin{array}{l}\text { Controls } \\
(n=15)\end{array}$ & $\begin{array}{l}\text { Remission } \\
(n=25)\end{array}$ & $\begin{array}{l}\text { Relapse } \\
(n=15)\end{array}$ \\
\hline \multicolumn{4}{|c|}{$\begin{array}{c}\text { Total Cholesterol } \\
\mathrm{mg} / \mathrm{dL}\end{array}$} \\
\hline Mean $\pm \mathrm{SD}$ & $137.86 \pm 14.85$ & $282.4 \pm 48.47$ & $422.33 \pm 50.17$ \\
\hline Range & $110-160$ & $\begin{array}{c}200-350 \\
* p<0.001\end{array}$ & $\begin{array}{c}300-500 \\
* p<0.001 \\
\dagger p<0.001\end{array}$ \\
\hline \multicolumn{4}{|l|}{ LDL-C mg/dL } \\
\hline Mean \pm SD & $71.06 \pm 8.68$ & $125.84 \pm 7.87$ & $143.86 \pm 10.88$ \\
\hline Range & $60-90$ & $\begin{array}{c}110-140 \\
* p<0.001\end{array}$ & $\begin{array}{c}120-160 \\
* p<0.001 \\
\dagger p<0.001\end{array}$ \\
\hline \multicolumn{4}{|l|}{ HDL-C mg/dL } \\
\hline Mean $\pm \mathrm{SD}$ & $60.33 \pm 5.86$ & $49.52 \pm 5.99$ & $30.24 \pm 6.33$ \\
\hline Range & $50-70$ & $\begin{array}{c}40-60 \\
* p<0.001\end{array}$ & $\begin{array}{c}20-40 \\
* p<0.001 \\
\dagger p<0.001\end{array}$ \\
\hline \multicolumn{4}{|l|}{$\mathrm{TG} \mathrm{mg} / \mathrm{dL}$} \\
\hline Mean \pm SD & $85.33 \pm 21.41$ & $215.40 \pm 24.53$ & $313.66 \pm 26.95$ \\
\hline Range & $50-120$ & $\begin{array}{c}180-255 \\
* p<0.001\end{array}$ & $\begin{array}{c}275-350 \\
* p<0.001 \\
\dagger p<0.001\end{array}$ \\
\hline \multicolumn{4}{|l|}{ apo-A-I mg/dL } \\
\hline $\begin{array}{l}\text { Mean } \pm \text { SD } \\
\text { Range }\end{array}$ & $\begin{array}{c}95.0 \pm 26.04 \\
50-140\end{array}$ & $\begin{array}{c}215.80 \pm 28.30 \\
160-265 \\
* p<0.001\end{array}$ & $\begin{array}{c}215.00 \pm 30.64 \\
160-270 \\
* p<0.001 \\
\dagger p \text { NS }\end{array}$ \\
\hline \multicolumn{4}{|l|}{ apo-B mg/dL } \\
\hline Mean $\pm \mathrm{SD}$ & $115.93 \pm 15.94$ & $141.40 \pm 27.45$ & $156.00 \pm 32.02$ \\
\hline Range & $80-130$ & $\begin{array}{c}100-180 \\
* p<0.01\end{array}$ & $\begin{array}{c}120-220 \\
* p<0.001 \\
\dagger p \text { NS }\end{array}$ \\
\hline
\end{tabular}

* Compared with controls.

$\dagger$ Remission versus relapse.

NS indicates not significant.

levels were significantly negatively correlated with albumin, GSH-PX, vitamins A, C, E, and HDL-C.

\section{DISCUSSION}

In the last few years, it has been proved that atherosclerotic changes begin to develop in childhood (24). Moreover, some clinical reports claim a high incidence of ischemic heart failure in adult nephrotic patients (8). Because the life expectancy of children and adolescents afflicted with NS has dramatically improved over the last $15 \mathrm{y}$, the occurrence of dyslipidemia with its associated morbidity is of particular concern (25).

Dyslipidemia is a contributory factor in the progression of initial glomerular injury in NS (26). An increase in peroxidation of lipids and lipoproteins may cause the release of ROS, which are strong oxidants that could result in proteinuria and glomerular injury via various mechanisms (27). These ROS can be generated either in the circulation or locally by glomerular cells. They promote cell injury by lipid peroxidation, which disrupts the structural integrity of the tubular epithelial cells and increases the glomerular permeability to proteins together with an alteration in glomerular hemodynamics (6).

The present study investigated the oxidant MDA and the antioxidants; albumin, GSH-PX, and vitamins C, A, and E, together with oxLDL and lipid profile in remission and relapse phases of SSNS (Tables 1-3). Significantly higher mean levels of MDA and lower mean levels of the various antioxidants were observed in SSNS children particularly in those at relapse phase. These findings are consistent with many previous studies $(1,3,6,28,29)$. Peroxidation of lipid membranes raises the concentration of the by-product MDA that results in lowering of the concentration of antioxidants because of consumption (6). Albumin is a leading preventive but not a chain breaking antioxidant of serum. In the present study, significantly lower levels of mean serum albumin were observed in relapse phase in comparison with those of the controls and remission phase. It is reported that even at very low concentrations, albumin has a high antioxidant activity (1). GSH-PX is a selenium-dependent enzyme thought to be critical in intracellular antioxidant defenses (30). Significantly lower mean serum levels of GSH-PX activity were found in SSNS particularly at relapse phase. This low GSH-PX activity levels may be a factor limiting the antioxidant capacity in NS $(28,31)$. Mean serum levels of antioxidant vitamins C, A, and $\mathrm{E}$ were significantly decreased in SSNS children especially in relapse phase (Table 2). These decreased levels suggest depletion, possibly because of consumption for neutralizing excessive circulating oxidants (3). Moreover, this could explain the significant negative correlations observed between MDA and the studied antioxidants (Table 4).

The lipids and apolipoprotein profile of SSNS children of the present study have revealed a pattern of abnormalities demonstrated by the significant increased mean serum levels of TC, LDL-C, TG, apo-A-I and apo-B, together with the significant decreased levels of HDL-C in both groups of SSNS children in comparison with those of the controls (Table 3). Significantly higher mean levels were observed in relapse group in comparison with those of the remission group, except for apo-A-I, apo-B, which showed no significant difference between remission and relapse, and HDL-C which was significantly lower in relapse group compared with remission group. These findings agree with previous reports $(8,26,32-$ 35). Although dyslipidemia is a common complication of NS, it is unclear whether it is a direct consequence of proteinuria or whether it arises secondarily from other effects of proteinuria such as reduced plasma oncotic pressure or hypoalbuminemia $(7,34)$. Although the observed negative correlation between serum albumin and lipid parameters in patients of the present study (Table 4) was described more than 40 y ago (36), no studies have clearly established a clear causal relationship between the rate of albumin synthesis and dyslipidemia in nephrotic patients (26). The increased levels of serum TC could be attributed to impairment of metabolism of mevalonate (cholesterol precursor) by the nephrotic kidney. This allows a greater cholesterol availability, that coupled with an enhanced hydroxy methyl glutaryl-CoA (HMG-CoA) reductase activity leads to increased hepatic cholesterol synthesis and unbalanced lipid homeostasis (26). In addition, the de- 
Table 4. Correlation coefficient ( $\mathrm{r}$ ) among various bioindices in children with steroid sensitive nephrotic syndrome

\begin{tabular}{|c|c|c|c|c|c|c|c|c|c|c|c|}
\hline MDA & ox-LDL & Albumin & GSH-PX & Vit-C & Vit-A & Vit-E & $\mathrm{TC}$ & LDL-C & HDL-C & TG & apo-A-I \\
\hline $\begin{array}{l}\text { ox-LDL } \\
\quad 0.951 \\
p<0.001\end{array}$ & & & & & & & & & & & \\
\hline $\begin{array}{l}\text { Albumin } \\
\qquad-0.901 \\
\quad p<0.001\end{array}$ & $\begin{array}{l}-0.929 \\
\quad p<0.001\end{array}$ & & & & & & & & & & \\
\hline $\begin{array}{l}\text { GSH-PX } \\
\quad-0.882 \\
p<0.001\end{array}$ & $\begin{aligned}-0.907 \\
\quad p<0.001\end{aligned}$ & $\begin{array}{l}0.895 \\
p<0.001\end{array}$ & & & & & & & & & \\
\hline $\begin{array}{l}\text { Vit-C } \\
\qquad \begin{array}{l}-0.894 \\
p<0.001\end{array}\end{array}$ & $\begin{array}{l}-0.914 \\
\quad p<0.001\end{array}$ & $\begin{array}{l}0.922 \\
p<0.001\end{array}$ & $\begin{array}{l}0.912 \\
p<0.001\end{array}$ & & & & & & & & \\
\hline $\begin{array}{l}\text { Vit-A } \\
\quad-0.859 \\
\quad p<0.001\end{array}$ & $\begin{array}{l}-0.854 \\
\quad p<0.001\end{array}$ & $\begin{array}{l}0.790 \\
p<0.001\end{array}$ & $\begin{array}{l}0.803 \\
p<0.001\end{array}$ & $\begin{array}{l}0.814 \\
p<0.001\end{array}$ & & & & & & & \\
\hline $\begin{array}{l}\text { Vit-E } \\
\qquad \begin{array}{l}-0.897 \\
p<0.001\end{array}\end{array}$ & $\begin{aligned}-0.842 \\
\quad p<0.001\end{aligned}$ & $\begin{array}{l}0.828 \\
p<0.001\end{array}$ & $\begin{array}{l}0.754 \\
p<0.001\end{array}$ & $\begin{array}{l}0.806 \\
p<0.001\end{array}$ & $\begin{array}{l}0.811 \\
p<0.001\end{array}$ & & & & & & \\
\hline $\begin{array}{l}\text { TC } \\
\quad 0.902 \\
\quad p<0.001\end{array}$ & $\begin{array}{l}0.915 \\
p<0.001\end{array}$ & $\begin{aligned} &-0.910 \\
& \quad p<0.001\end{aligned}$ & $\begin{array}{l}-0.886 \\
\quad p<0.001\end{array}$ & $\begin{array}{l}-0.935 \\
\quad p<0.001\end{array}$ & $\begin{array}{l}-0.802 \\
\quad p<0.001\end{array}$ & $\begin{array}{l}-0.817 \\
\quad p<0.001\end{array}$ & & & & & \\
\hline $\begin{array}{l}\text { LDL-C } \\
\quad 0.929 \\
\quad p<0.001\end{array}$ & $\begin{array}{l}0.904 \\
p<0.001\end{array}$ & $\begin{aligned}-0.887 \\
\quad p<0.001\end{aligned}$ & $\begin{array}{l}-0.874 \\
\quad p<0.001\end{array}$ & $\begin{array}{l}-0.876 \\
\quad p<0.001\end{array}$ & $\begin{array}{l}-0.810 \\
\quad p<0.001\end{array}$ & $\begin{array}{l}-0.841 \\
\quad p<0.001\end{array}$ & $\begin{array}{l}0.891 \\
p<0.001\end{array}$ & & & & \\
\hline $\begin{array}{l}\text { HDL-C } \\
\quad-0.822 \\
p<0.001\end{array}$ & $\begin{array}{l}-0.852 \\
\quad p<0.001\end{array}$ & $\begin{array}{l}0.903 \\
p<0.001\end{array}$ & $\begin{array}{l}0.867 \\
p<0.001\end{array}$ & $\begin{array}{l}0.876 \\
p<0.001\end{array}$ & $\begin{array}{l}0.776 \\
p<0.001\end{array}$ & $\begin{array}{l}0.743 \\
p<0.001\end{array}$ & $\begin{array}{l}-0.880 \\
\quad p<0.001\end{array}$ & $\begin{array}{l}-0.868 \\
\quad p<0.001\end{array}$ & & & \\
\hline $\begin{array}{l}\text { TG } \\
\qquad \begin{array}{l}0.883 \\
p<0.001\end{array}\end{array}$ & $\begin{array}{l}0.918 \\
p<0.001\end{array}$ & $\begin{aligned} &-0.911 \\
& \quad p<0.001\end{aligned}$ & $\begin{array}{l}-0.901 \\
\quad p<0.001\end{array}$ & $\begin{array}{l}-0.929 \\
\quad p<0.001\end{array}$ & $\begin{array}{l}-0.792 \\
\quad p<0.001\end{array}$ & $\begin{array}{l}-0.736 \\
p<0.001\end{array}$ & $\begin{array}{l}0.911 \\
p<0.001\end{array}$ & $\begin{array}{l}0.870 \\
p<0.001\end{array}$ & $\begin{array}{l}-0.902 \\
\quad p<0.001\end{array}$ & & \\
\hline $\begin{array}{l}\text { apo-A-I } \\
\quad 0.527 \\
p<0.01\end{array}$ & $\begin{array}{l}0.414 \\
p<0.05\end{array}$ & $\begin{array}{r}-0.30 \\
\mathrm{NS}\end{array}$ & $\begin{array}{l}-0.384 \\
\quad p<0.05\end{array}$ & $\begin{array}{l}-0.337 \\
\quad p<0.05\end{array}$ & $\begin{aligned}-0.626 \\
\quad p<0.001\end{aligned}$ & $\begin{array}{l}-0.564 \\
\quad p<0.01\end{array}$ & $\begin{array}{l}0.327 \\
p<0.05\end{array}$ & $\begin{array}{l}0.495 \\
p<0.01\end{array}$ & $\begin{array}{l}-0.350 \\
\quad p<0.05\end{array}$ & $\begin{array}{r}0.288 \\
\text { NS }\end{array}$ & \\
\hline $\begin{array}{l}\text { apo-B } \\
\quad 0.596 \\
p<0.01\end{array}$ & $\begin{array}{l}0.521 \\
p<0.01\end{array}$ & $\begin{array}{l}-0.475 \\
\quad p<0.01\end{array}$ & $\begin{array}{l}-0.556 \\
\quad p<0.01\end{array}$ & $\begin{array}{l}-0.501 \\
\quad p<0.01\end{array}$ & $\begin{array}{l}-0.561 \\
\quad p<0.01\end{array}$ & $\begin{array}{l}-0.570 \\
p<0.01\end{array}$ & $\begin{array}{l}0.526 \\
p<0.01\end{array}$ & $\begin{array}{l}0.601 \\
p<0.001\end{array}$ & $\begin{array}{l}-0.445 \\
\quad p<0.01\end{array}$ & $\begin{array}{l}0.492 \\
p<0.01\end{array}$ & $\begin{array}{l}0.564 \\
p<0.01\end{array}$ \\
\hline
\end{tabular}

Pearson correlation was used.

creased activity of the enzyme lecithine-cholesterol acyltransferase reported in NS could account for the several lipoprotein abnormalities observed in that syndrome (37). Elevation of LDL-C in NS has been suggested to be caused by at least two independent mechanisms, impairment of LDL-C catabolism because of reduced LDL receptor activity secondary to intrahepatic cholesterol expansion. The impairment of LDL catabolism may, also, be because of a defective ligand-receptor interaction through alteration of the conformation of apo-B on the particle surface (38). The other mechanism is the increased activity of cholesterol ester transfer protein (CETP) [an enzyme that catalyzes the exchange of cholesterol ester rich core of $\mathrm{HDL}_{2}$ for the triglyceride rich core of very LDL (VLDL) remnant particles yielding LDL] in nephrotic patients, thus accelerating the normal pathway for LDL synthesis (33).

In addition, significant higher mean serum levels of oxidized LDL were observed in both the studied groups of SSNS children in comparison with those of the controls, with significant higher levels in relapse group (Table 1). The increased serum levels of oxLDL in NS could be attributed to the significant disturbances in oxidant status during NS (29). OxLDL is commonly thought to represent the initial step of oxidative LDL modification (9). Studies in the last few years have suggested that oxLDL may be critically involved in the progression of glomerulosclerosis. Moreover, Lee et al., (39) reported that LDL oxidation might have a fundamental role in the formation of early atherosclerotic lesions and their progression. This could constitute an important link between NS and atherosclerosis (29).

As regards TG, significantly higher mean serum levels of TG were observed in both the groups of the studied patients particularly in those with relapse (Table 3). Hypertriglyceridemia in the NS is primarily a result of decreased catabolism confirming the observation of Yoshino et al. (40) that it is not caused by increased VLDL secretion. In addition, the decreased lipoprotein catabolism in NS, also caused by decreased clearance of VLDL resulted both from decreased binding of lipoprotein lipase (LpL) to endothelial surfaces in the presence of a reduced oncotic pressure and/or hypoalbuminemia and from an alteration of VLDL binding to endothelium-bound LpL (41). These combined defects may act together to cause the profound defect in lipoprotein catabolism responsible for hypertriglyceridemia in NS $(26,34)$. The influence of NS on HDL-C metabolism is still unclear; decreased as well as normal or elevated HDL-C levels were reported in previous studies $(7,8,32)$. 
The present study showed significantly lower mean serum levels of HDL-C in SSNS children particularly in those in relapse in comparison with those of the controls and remission (Table 3). HDL-C is an effective antioxidant with the capacity to inhibit the oxidative modification of LDL. HDL-C, also, possesses anti-inflammatory properties. These antioxidant and anti-inflammatory properties of HDL-C may be as important as its cholesterol efflux function in terms of protecting against the development of atherosclerosis (42). Abnormally high excretion of HDL through the damaged glomeruli could be a possible explanation for the reduced serum HDL-C observed in NS (43).

The present study also revealed significantly increased mean serum levels of apo-A-I and apo-B in SSNS children in comparison with those of the controls, with no significant differences between remission and relapse group (Table 3 ). These findings agree with those of Merouani et al., (8), Kaysen and de Sain-van der Velden (33), and Marsh et al. (38). However, the apo-A-I findings disagree with those of Abdel Ghany et al., (32) and Zhang et al., (44), as they reported decreased levels of apo-A. However, the increased apo-A-I and apo-B in NS could be explained by the hypothesis that changes in plasma oncotic pressure following hypoalbuminemia and may be involved in stimulating the transcription of a group of liver secreted proteins $(38,45)$.

The findings of the present study showed that there is increased oxidative stress during NS with improvement during remission as evidenced biochemically by lower levels of MDA and oxLDL, higher levels of the studied antioxidants and lower levels of lipid profile than those of the relapse group. However, despite the use of glucocorticoids, no normalization of the studied bioindices was observed in remission. The exact mechanism of action of prednisolone in NS has not been elucidated yet, although it is believed to be caused by immunosuppressive and antiinflammatory properties (3). Moreover, the results of some experimental studies suggest that steroids directly or indirectly impair the antioxidant reactions and lead to overproduction of ROS $(46,47)$. However, the study of Kawamura et al. (48) suggested that glucocorticoids may have a therapeutic role through the stimulation/augmentation of the activity of antioxidant enzymes. In addition, the study of Ece et al. (1) observed that steroid treatment did not suppress oxidative stress in SSNS.

In conclusion, the findings of the present study display an increased oxidative stress and decreased antioxidant response in SSNS. Additionally, although there is clinical remission no normalization of the biochemical indices was observed despite the use of glucocorticoids. Therefore, there might be a potential role for regular lipid monitoring during the follow-up of nephrotic patients especially those with frequent relapses to identify high-risk patients, who should be evaluated as candidates for a lipid lowering therapy. Therefore, the present study recommends the combined use of steroid, antioxidant therapy, and lipid lowering therapy in such children.

\section{REFERENCES}

1. Ece A, Atamer Y, Gurkan F, Davutoglu M, Kocyigit Y, Tutanc M 2005 Paraoxonase, total antioxidant response and peroxide levels in children with steroid-sensitive nephrotic syndrome. Pediatr Nephrol 20:1279-1284

2. Kinra S, Rath B, Kabi BC 2000 Indirect quantification of lipid peroxidation in steroid responsive nephrotic syndrome. Arch Dis Child 82:76-78

3. Mathew JL, Kabi BC, Rath B 2002 Anti-oxidant vitamins and steroid responsive nephrotic syndrome in Indian children. J Paediatr Child Health 38:450-457

4. Ohtake T, Kumura M, Nishimura M, Hishida A 1997 Roles of reactive oxygen species and antioxidant enzymes in murine daunomycin induced nephropathy. J Lab Clin Med 129:81-88

5. Zima T, Tesar V, Stipek S 1997 The influence of cyclosporine on lipid peroxidation and superoxide dismutase in adriamycin nephropathy in rats. Nephron 75:464-469

6. Ece A, Atamer Y, Gurkan F, Bilici M, Kocyigit Y 2004 Anti-oxidant status in relation to lipoproteins, leptin and pro-inflammatory cytokines in children with steroid-sensitive nephritic syndrome. Nephrology 9:366-373

7. Kronenberg F 2005 Dyslipidemia and nephrotic syndrome: recent advances. J Ren Nutr 15:195-203

8. Merouani A, Levy E, Mongeau JG, Robitaille P, Lambert M, Delvin EE 2003 Hyperlipidemic profiles during remission in childhood idiopathic nephrotic syndrome. Clin Biochem 36:571-574

9. Vicca S, Massy ZA, Hennequin C, Rihane D, Nguyen-Khoa T, Drueke TB, Lacour B 2003 New insights into the effects of the protein moiety of oxidized LDL (oxLDL). Kidney Int Suppl 63:S125-S127

10. Verrotti A, Basciani F, Trotta D, Pomilio MP, Morgese G, Chiarelli F 2002 Serum copper, zinc, selenium, glutathione peroxidase and superoxide dismutase levels in epileptic children before and after 1 y of sodium valproate and carbamazepine therapy. Epilepsy Res 48:71-75

11. Buege JA, Aust SD 1978 Microsomal lipid peroxidation. Methods Enzymol 52:302310

12. Craig WY, Poulin SE, Nelson CP, Ritchie RF 1994 An ELISA method for the detection and quantization of IgG antibody against oxidized LDL: the effects of blocking buffer and the method of data expression on experimental findings. Clin Chem 40:882-888

13. Doumas BT, Walson WA, Biggs HG 1971 Albumin standards and the measurement of serum albumin with bromocresol green. Clin Chim Acta 31:87-96

14. Mills GC 1959 The purification and properties of glutathione peroxidase of erythrocyte. J Biol Chem 234:502-506

15. Hafeman DG, Sunde RA, Hockstka W 1974 Effect of dietary selenium on erythrocyte and liver glutathione peroxidase in the rat. J Nutr 104:580-587

16. Roe JH 1961 Standard Methods of Clinical Chemistry. Vol. III. Academic press, New York, pp 35

17. Nino HV, Parasad AS 1980 Vitamins and trace elements. In Sonnenwirth AC, Leonard J (eds) Gradwohl's Clinical Laboratory Methods and Diagnosis. 8th ed. Mosby Company, St. Louis, Missouri, pp 368

18. Baker SJ, Pereira SM, Begum A 1968 Failure of vitamin E therapy in the treatment of anemia of protein-calorie malnutrition. Blood 32:717-725

19. Assmann G, Jabs HV, Kohnert V, Nolte W, Schriewer H 1984 LDL-cholesterol determination in blood serum following precipitation of LDL with polyvinylsulfate. Clin Chim Acta 140:77-83

20. Grove TH 1979 Effect of reagent $\mathrm{pH}$ on determination of HDL-cholesterol by precipitation with sodium phosphotungestate-magnesium. Clin Chem 25:560-564

21. Allain CC, Poon LS, Chan CS, Richmond W, Fu PC 1974 Enzymatic determination of total serum cholesterol. Clin Chem 20:470-475

22. Bucolo G, David H 1973 Quantitative determination of serum triglycerides by use of enzymes. Clin Chem 19:476-482

23. Marcovina SM, Albers JJ, Dati F, Ledue TB, Richite RF 1991 International Federation of Clinical Chemistry Standardization Project for measurements of apo-A-I and B. Clin Chem 37:1676-1682

24. Imakita M, Yutani C, Strong JP, Sakurai I, Sumiyoshi A, Watanabe T, Mitsumata M, Kusumi Y, Katayama S, Mano M, Baba S, Mannami T, Tanaka K 2001 Second nation-wide study of atherosclerosis in infants, children and young adults in Japan. Atherosclerosis 155:487-497

25. Muntner P, Coresh J, Smith C, Eckfeldt J, Klag MJ 2000 Plasma lipids and risk of developing renal dysfunction. The atherosclerosis risk in communities study. Kidney Int 58:293-301

26. Delvin EE, Merouani A, Levy E 2003 Dyslipidemia in pediatric nephrotic syndrome: causes revisited. Clin Biochem 36:95-101

27. Diamond JR 1992 The role of reactive oxygen species in animal models of glomerular disease. Am J Kidney Dis 19:292-300

28. Fydryk J, Jacobson E, Kurzawska O, Malecka G, Gonet B, Urasiński T, Brodkiewicz A, Bukowska H 1998 Antioxidant status of children with steroid sensitive nephrotic syndrome. Pediatr Nephrol 12:751-754

29. Skrzep-Poloczek B, Tomasik A, Tarnawski R, Hyla-Klekot L, Dyduch A, Wojciechowska C, Wesolowski W, Kopieczna-Grzebieniak E, Zalejska-Fiolka J, Widera E 2001 Nephrotic origin hyperlipidemia, relative reduction of vitamin E level and subsequent oxidative stress may promote atherosclerosis. Nephron 89:68-72

30. Bayse CA, Baker RA, Ortwine KN 2005 Relative strengths of se...N,O interactions; Implications for glutathione peroxidase activity. Inorganica Chim Acta 358:38493854

31. Fydryk J, Olszewska M, Urasinski T, Brodkiewicz A 2003 Serum selenium level and glutathione peroxidase activity in steroid-sensitive nephrotic syndrome. Pediatr Nephrol 18:1063-1065 
32. Abdel Ghany SM, Sobh MA, Al-Kareemy EA, Abdul-Nassar MA, Kilani AI 1992 Evaluations of changes in lipid profile and thyroid hormones in nephrotic syndrome. Assiut Med J 16:11-27

33. Kaysen GA, de Sain-van der Velden MG 1999 New insights into lipid metabolism in the nephrotic syndrome. Kidney Int Suppl 71:S18-S21

34. Shearer GC, Stevenson FT, Atkinson DN, Jones H, Staprans I, Kaysen GA 2001 Hypoalbuminemia and proteinuria contribute separately to reduced lipoprotein catabolism in the nephrotic syndrome. Kidney Int 59:179-189

35. Kronenberg F, Lingenhel A, Lhotta K, Rantner B, Kronenberg MF, Konig P, Thiery J, Koch M, Von Eckardstein A, Dieplinger H 2004 Lipoprotein(a)- and LDL-derived cholesterol in nephrotic syndrome: Impact on lipid-lowering therapy? Kidney Int $66: 348-354$

36. Baxter JH, Goodman HC, Havel RJ 1960 Serum lipid and lipoprotein alterations in nephrosis. J Clin Invest 39:455-465

37. Vaziri ND, Liang K, Parks JS 2001 Acquired lecithin-cholesterol acyltransferase deficiency in nephrotic syndrome. Am J Physiol Renal Physiol 280:F823-F828

38. Marsh JB, Welty FK, Lichtenstein AH, Lamon-Fava S, Schaefer EJ 2002 Apolipoprotein B metabolism in humans: studies with stable isotope-labeled amino acid precursors. Atherosclerosis 162:227-244

39. Lee CM, Chien CT, Chang PY, Hsieh MY, Jui HY, Chau-Song Liau CS, Hsu SM, Lee YT 2005 HDL antagonizes oxidized LDL by suppressing oxygen free-radical formation and preserving nitric oxide bioactivity. Atherosclerosis 183:251-258

40. Yoshino G, Hirano T, Nagata K 1993 Hypertriglyceridemia in nephrotic rats is due to clearance defect of plasma triglyceride: overproduction of triglyceride-rich lipoprotein is not an obligatory factor. J Lipid Res 34:875-884
41. Kaysen GA, Pan XM, Couser WG, Staprans I 1993 Defective lipolysis persists in hearts of rats with heymann nephritis in the absence of nephrotic plasma. Am Kidney Dis 22:128-134

42. Barter PJ, Nicholls S, Rye KA, Anantharamaiah GM, Navab M, Fogelman AM 2004 Anti-inflammatory Properties of HDL. Circ Res 95:764-788

43. Nayak SS, Bhaskaranand N, Baliga M, Venkatesh A, Aroor AR 1988 Serum HDL-cholesterol and urinary cholesterol in nephrotic syndrome. Indian J Med Res $88: 150-155$

44. Zhang H, Huang WC, Tang SC 1994 (Serum apolipoprotein abnormalities in patients with idiopathic nephrotic syndrome). Zhonghua Yi Xue Za Zhi 74:542-544, 582-583

45. Kim BJ, Hwang ST, Sung KC, Kim BS, Kang JH, Lee MH, Park JR 2005 Comparison of the relationships between serum apolipoprotein B and serum lipid distributions. Clin Chem 51:2257-2263

46. Orzechowski A, Ostaszewski P, Wilczak J, Jank M, Balastinska B, Wareski P, Fuller JJ 2002 Rats with glucocorticoid-induced catabolic state show symptoms of oxidative stress and spleen atrophy: the effect of age and recovery. J Vet Med A Physiol Pathol Clin Med 49:256-263

47. Iuchi T, Akaike M, Mitsui T, Ohshima Y, Shintani Y, Azuma H, Matsumoto T 2003 Glucocorticoid excess induces superoxide production in vascular endothelial cells and elicits vascular endothelial dysfunction. Circ Res 92:81-87

48. Kawamura T, Yoshioka T, Bills T, Fogo A, Ichikawa I 1991 Glucocorticoid activates glomerular antioxidant enzymes and protects glomeruli from oxidant injuries. Kidney Int 40:291-301 